\title{
Prevalence, Stage and Sociodemographic Pattern of Breast Cancer in a Tertiary Health Institution, South West Nigeria
}

\author{
Ndidi Okunnuga ${ }^{1}$, Adetokunbo Okunnuga ${ }^{2}$, Salewa Osho $^{3}$, Patrick Olanrewaju Osho ${ }^{4}$, \\ Omolayo Olubosede ${ }^{5}$ \\ ${ }^{1}$ Department of Radiation and Clinical Oncology, University of Medical Science, Akure, Nigeria \\ ${ }^{2}$ Department of Histopathology, Federal Teaching Hospital, Ido, Nigeria \\ ${ }^{3}$ Department of Radiology, University of Medical Science Teaching Hospital, Akure, Nigeria \\ ${ }^{4}$ Department of Haematology and Virology, University of Medical Science Teaching Hospital, Akure, Nigeria \\ ${ }^{5}$ Department of Paediatric, University of Medical Science Teaching Hospital, Akure, Nigeria
}

Email address:

droshopo@gmail.com (P. O. Osho)

${ }^{*}$ Corresponding author

\section{To cite this article:}

Ndidi Okunnuga, Adetokunbo Okunnuga, Salewa Osho, Patrick Olanrewaju Osho, Omolayo Olubosede. Prevalence, Stage and Sociodemographic Pattern of Breast Cancer in a Tertiary Health Institution, South West Nigeria. International Journal of Clinical Oncology and Cancer Research. Vol. 6, No. 3, 2021, pp. 109-114. doi: 10.11648/j.ijcocr.20210603.11

Received: May 5, 2021; Accepted: May 24, 2021; Published: July 9, 2021

\begin{abstract}
Background: Breast cancer is the commonest cancer found amongst women in Nigeria. It is a major cause of cancer mortality. The prevalence and presentation of breast cancer varies with the Socio-demographic pattern. The stage at presentation also determines the outcome. The burden of Breast cancer is high among women of all age groups in Nigeria. The prevalence of Breast cancer among women in Ondo state South West Nigeria is increasing and majority of the women present in the advance form of the disease. Objectives: To determine the Prevalence, stage and Sociodemographic factors associated with Breast Cancer. Method: The study is a retrospective analysis of clinical records of confirmed breast cancer patients between March 2013 and April 2019 attending the Oncology outpatient clinic at University of Medical Science Teaching Hospital, Akure, Ondo state Nigeria. The socio-demographic data were collated and analyzed. Results: A total of Four hundred breast cancer patients were seen. Their ages ranged from 20 to 89 years with a (mean age of $48.4+/-12.9$ years). The Median age of 49.4 years. $99 \%$ were females and majority $(68 \%)$ was premenopausal. Those younger than 40 years constituted $37.5 \%$ of the sample population while those older constituted $74.5 \%$. The peak age of incidence was in the $4^{\text {th }}$ decade. Majority of the participants $53.2 \%$ completed secondary education and $43 \%$ of the population had stage 4 disease. Conclusion: Breast cancer is the commonest cancer in women. The level of education does not correlate with a better knowledge of the disease and majority of the women presented with advance stage of the disease.
\end{abstract}

Keywords: Breast Cancer, Stage, Socio-demographic Factors

\section{Introduction}

Breast cancer is the most frequently diagnosed cancer in Nigeria. It is the most common malignancy in women and the leading cause of cancer deaths worldwide [1, 2] It accounts for $16 \%$ of all female cancers and $60 \%$ death occurs in developing countries [3,4] Breast cancers causes 376,000 deaths a year and approximately 900,000 to $1,000,000$ women are diagnosed worldwide every year with the disease $[5,6]$.
The incidence of breast cancer is lower in developing countries than in developed countries, yet mortality is higher in developing countries than the developed due to late presentation and diagnosis in developing countries [1]. The overall Breast cancer mortality rate in Nigeria is also considered to be relatively high. In America 19\% of all Breast cancer results in death. In Nigeria it is 51\% [7].

The peak incidence of the disease in Nigeria is at least a decade earlier compared to the Caucasians [8].

In Nigeria late diagnosis is a major factor for high 
mortality seen in patients with breast cancer this is partly attributed to inadequate awareness and a lack of populationwide Breast cancer screening program $[9,10]$.

The low morbidity and mortality found in developed countries is due to the high literacy rate and better screening programs. In recent times the incidence, prevalence, sociodemographic and mortality of breast cancer in Nigeria has been based on estimates from case series, medical records, mortality records, and hospital based cancer registries [11].

Despite the intensified health education on breast cancer more than $50 \%$ of breast cancer patients present with advance stage of the disease [12-14] Most, 56\% of newly reported breast cancer cases occur in the developing countries like Nigeria. It is estimated that by $2030,70 \%$ of all cancer cases will be found in developing countries [15] Most of this increase in incidence growth is due to increase in population and life expectancy [11].

Socio-demographic features

Breast cancer affects women more than men. Breast cancer in men is rare and accounts for $0.6 \%$ of breast cancer cases [2, 12] In Africa breast cancer is more common in young premenopausal women and more common in menopausal women in advance countries [2, 12, 16, 17].

One of the most important risk factors of breast cancer is age and it increases with age [2, 18] Most cases of breast cancer occurs between the age of 45 and 65 years and this is due to hormonal imbalance during menopause.

Socioeconomic status weakly affects the risk of breast cancer disease. Diet that contains excessive fat increases the risk of developing breast cancer. Women with high levels of education have more knowledge of breast cancer and thus present early in the disease [14, 19] unmarried women or Nulliparous women have a higher risk of developing breast cancer. Studies have shown that married women present early probably due to the financial social support from their spouses [2, 19].

Breast cancer presentation may be influenced by religion and the distance between home and hospital. Religious women are more likely to present late to hospital with breast cancer [16]. Fear of mastectomy and attendance at prayer camps were found as the two most prominent causes for late presentation in a study conducted in Lagos [12].

Stage of presentation and socio-demographic characteristics

There is an association between the socio-demographic characteristics and stage of presentation of breast cancer. The older the age groups the more the delay in presentation. Tumour stage at presentation remains one of the major prognostic factors and women with early stage breast cancer are expected to have excellent survival rates [20].

Several studies have identified stage at presentation as an important factor in survival differences between socioeconomic groups $[20,21]$ Low socioeconomic status is strongly associated with delay in presentation of breast cancer. Other factors associated delay in presentation is lack of access to health care and lack of knowledge of symptoms of breast cancer [13].

The pattern of presentation
The incidence of breast cancer is rising over the last decade. There have been more deaths from breast cancer in developing nations with over $87 \%$ of women presenting with advanced stages of the disease [12, 13]. In emerging countries, the rate of occurrence is increasing. Late menarche, early menopause, high parity, irregular menses and prolonged breast feeding are all protective reproductive histories $[1,20$, 21].

Invasive ductal carcinoma is the most common histological type of breast cancer worldwide accounts for $70 \%$ other types are tubular, mucinous, lobular, medullary and papillary cancers others are mixed epithelial and connective tissue.

A major goal of health care system is to equally improve the health in all groups of the population they serve [22] despite these aim socioeconomic and demographic health inequalities in Breast cancer detection and survival have been assessed all over the world [23, 24].

Therefore this study aims to evaluate the Prevalence, Socio-demographic pattern and stage of presentation of breast cancer among patients diagnosed from 2013 to2019 at a Tertiary hospital facility.

\section{Aim}

To study the Prevalence of Breast cancer in Ondo state.

To determine the stage at presentation and

To identify the socio-demographic factors associated with Breast cancer.

\section{Material and Method}

This is a descriptive retrospective study carried out at the University of Medical Science Teaching hospital, Akure, Ondo state. The hospital is a tertiary institution located in an urban area of Ondo state and serves as a referral center for the primary and secondary health facilities in Ondo state and other neighboring states like Ekiti, Osun, Kwara, Edo in Southern Nigeria. The study analyzed all patients with histologically confirmed breast cancer who were managed in our hospital from March 2013 to April 2019. All cases with benign breast lesions and suspected cases of breast cancer with no histology report were excluded from the study.

The study population included 400 clinical records of patients with breast cancer from the period of 2013 to 2019 . Socio-demographic data extracted included; Age, sex, site, stage at diagnosis, level of educational and occupation, religion, marital status, Obstetrics and gynecology history, histological type, parity, place of residence and family history.

Approval for the study was granted by the University of Medical science Teaching Hospital Ethics and Research Committee.

\section{Results}

A total of 400 patients with histological diagnosis of confirmed Breast cancer cases were seen. Their ages ranged 
between 20 years to 89 years with a mean age of 48.4 years, with a standard deviation of 12.9. Those younger than 40 years constituted $37.5 \%$ of the sample while those older constituted $74.5 \%$. There is a similar distribution at the $3^{\text {rd }}$ decade and $5^{\text {th }}$ decade.

Majority of the participants $53.2 \%$ completed secondary education while $39.5 \%$ and $7.3 \%$ for Tertiary and Primary education respectively. $85.7 \%$ were married, while single, widow and divorced constitute $2.8 \%, 8 \%$ and $3.5 \%$ respectively. Only $31 \%$ of the population was in menopause while $68 \%$ were premenopausal. Majority of the population presented at late stage of the disease.

The Socio-demographic data of the patients are seen in the table below.

Table 1. Frequency distribution by Age.

\begin{tabular}{lll}
\hline AGE (Years) & Number & \% \\
\hline $20-29$ & 16 & 04 \\
$30-39$ & 86 & 21.5 \\
$40-49$ & 134 & 33.5 \\
$50-59$ & 85 & 21.3 \\
$60-69$ & 56 & 14 \\
$70-79$ & 15 & 3.7 \\
$80-89$ & 08 & 02 \\
TOTAL & 400 & 100 \\
\hline
\end{tabular}

Table 2. Distribution of the level of education.

\begin{tabular}{lll}
\hline LEVEL OF EDUCATION & Number & $\mathbf{\%}$ \\
\hline PRIMARY & 29 & 7.3 \\
SECONDARY & 213 & 53.2 \\
TERTIARY & 158 & 39.5 \\
TOTAL & 400 & 100 \\
\hline
\end{tabular}

Table 3. Distribution of the marital status.

\begin{tabular}{lll}
\hline MARITAL STATUS & Number & \% \\
\hline SINGLE & 11 & 2.8 \\
MARRIED & 343 & 85.7 \\
WIDOW & 32 & 08 \\
DIVORCED & 14 & 3.5 \\
TOTAL & 400 & 100 \\
\hline
\end{tabular}

Table 4. Parity Distribution.

\begin{tabular}{lll}
\hline PARITY & Number & \% \\
\hline 0 & 23 & 5.7 \\
1 & 08 & 02 \\
2 & 54 & 13.5 \\
3 & 156 & 39 \\
4 & 101 & 25.3 \\
5 & 51 & 12.7 \\
6 & 07 & 1.8 \\
Total & 400 & 100 \\
\hline
\end{tabular}

Table 5. Distribution of participants occupation.

\begin{tabular}{lll}
\hline OCCUPATION & Number & $\mathbf{\%}$ \\
\hline Teacher & 41 & 10.2 \\
Housewife & 89 & 22.3 \\
Civil servant & 55 & 13.7 \\
Artisan & 37 & 9.3 \\
Trader/ Private business & 178 & 44.5 \\
Total & 400 & 100 \\
\hline
\end{tabular}

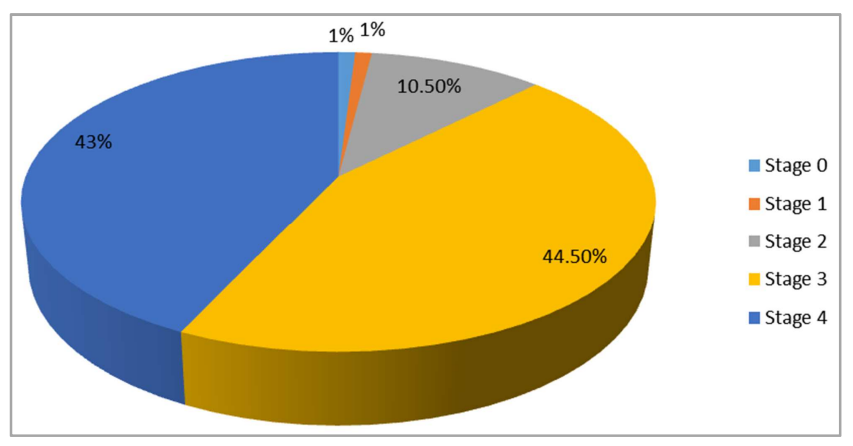

Figure 1. Distribution of The stage of Breast cancer.

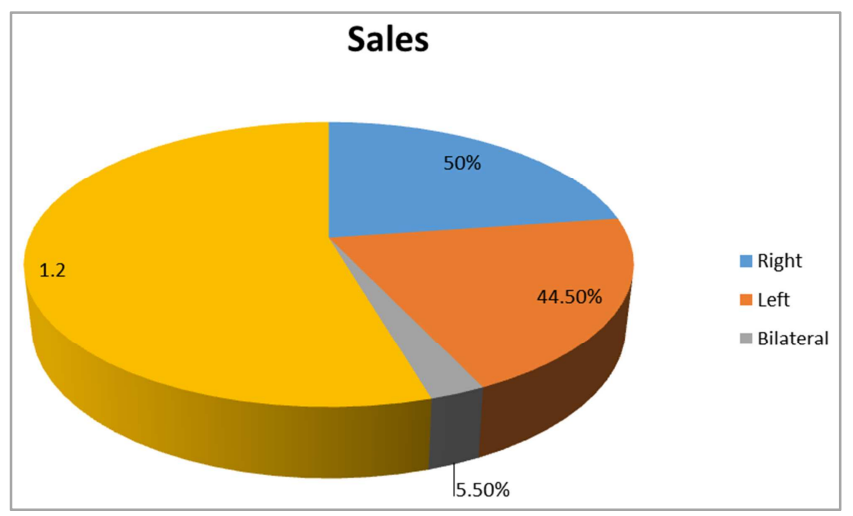

Figure 2. Distribution of Site of Primary disease.

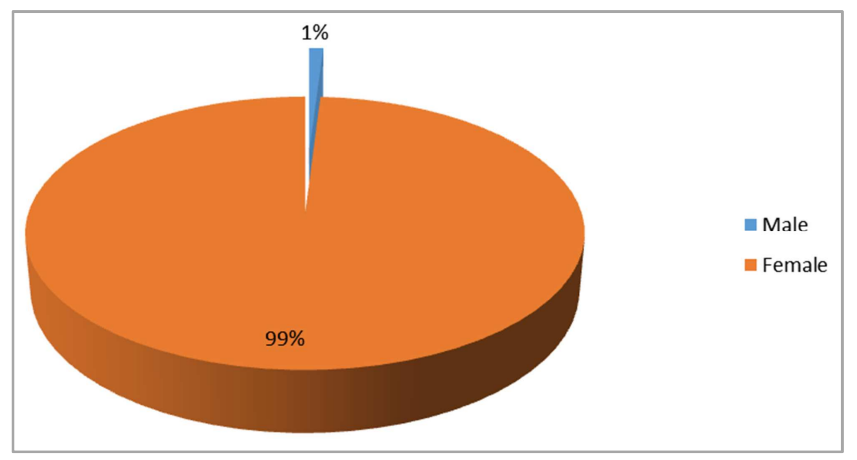

Figure 3. The sex distribution.

Table 6. Distribution of the Histological type of Breast Cancer.

\begin{tabular}{lll}
\hline HISTOLOGICAL TYPE & NUMBER & \% \\
\hline Invasive ductal ca. & 373 & 93.3 \\
Invasive lobular ca. & 10 & 2.5 \\
Spindle cell ca. & 03 & 0.7 \\
Mucinous ca. & 02 & 0.5 \\
Papillary ca. & 02 & 0.5 \\
Colloid ca. & 01 & 0.3 \\
Medullary ca. & 02 & 0.5 \\
Fibrosarcoma & 03 & 0.7 \\
Carcinoma in-situ & 04 & 1.0 \\
Total & 400 & 100 \\
\hline
\end{tabular}

Table 7. The Distribution of the Gynaecological history Patter.

\begin{tabular}{lll}
\hline GYNAECOLOGY HISTORY & NUMBER & \% \\
\hline Pre-menopausal & 272 & 68 \\
Menopausal & 124 & 31 \\
None & 04 & 1 \\
TOTAL & 400 & 100 \\
\hline
\end{tabular}




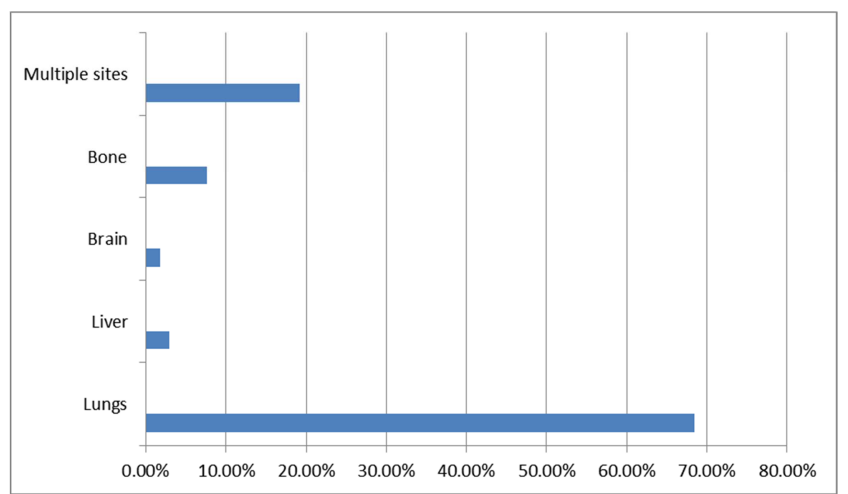

Figure 4. Distribution of the Site of Metastasis.

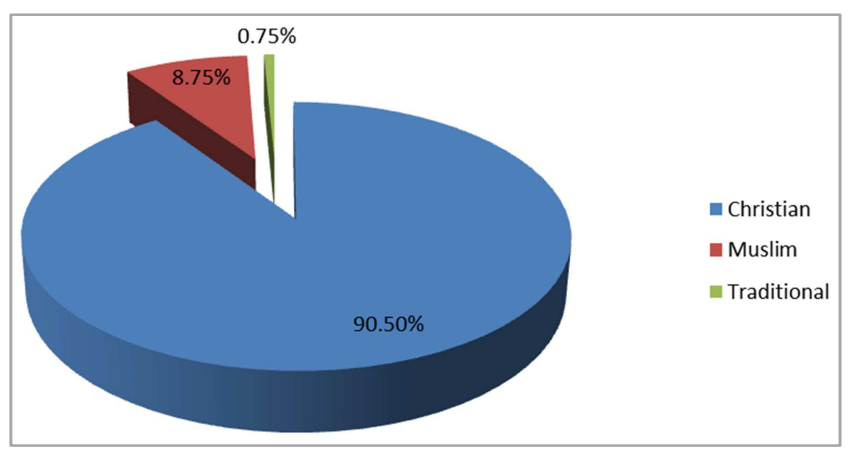

Figure 5. Distribution of Religion Pattern.

\section{Discussion}

Breast cancer is the most commonly diagnosed cancer and the leading cause of cancer death in women. It accounts for $23 \%$ of total cancers and $14 \%$ of all cancer related death [25]. In this study the socio-demographic characteristics as shown in (Table 1) the majority of the patients' fall between ages 40 to 49 years, whereas the minority was between the ages 80 to 89 years. The mean age was 48.4 years SD +/-12.9. In a study by Jignasal Amrutal et al (2016) the mean age was 49 years and the age range in the study was 21 to 89 years [26].

A study by Olaogun et al noted that the peak incidence was in the $4^{\text {th }}$ decade with a mean age of 48 years [27]. This was similar to our study.

The median age in our study was 49.4 years. In the UK the British black women also presented younger at a median age of 46 years than white patients at a median age of 67 year [28]

In a study by Augustine Baleakouzo et al (2014) it revealed a mean age of 45.83 years SD+/- 13.5 [29]. The majority of the study population was within 45 to 54 years of age. 30 This is similar to our study. A mean age of $50.1 \mathrm{SD}+/-12.1$ years was noted in a study by Mohammed Taroneh et al (2011) and more than $50 \%$ of the study population was above 50 years [30].

A study in Baghdad by Usama M Al-fadhi et al (2016) noted that the mean age was 56 years and the highest frequency was between 50 to 59 years [31].

It is noted that the incidence increases with age. In Nigeria where the life expectancy is relatively low, we still see women older than 70 years presenting with Breast cancer. Breast cancer in women younger than 35 years is uncommon and it accounts for $2 \%$ of all breast cancer in advance countries [32] The proportion of women younger than age 30 years old in this study is $4 \%$ and this comparable to that in the study by Das et al [32]. This is higher than prescribed western data of $1 \%$ to $2 \%$.

In a study by Anital Feller et al (2017) it was noted that women younger than 50 years accounted for $21.7 \%$ of the population and majority $(53.3 \%)$ were between the ages of 50 to 69 years [33].

In this study we saw that majority $(53.2 \%)$ of the women had Secondary school education while $39.5 \%$ had Tertiary education. This was similar to a study by Usama M Al-fadhi who noted that majority $(54.8 \%)$ of the participants had secondary education. A contrary result was seen by Aleyama Mathew et al (2015) who stated that majority (26\%) of the respondent had tertiary education [34] In a study by Augustine Baleakouzo et al 14\% had tertiary education [35]. In a study by Olaogun et al majority (64.6\%) of the patients had at least a secondary shool education [26]. While Adisa et al 41 in Ile- Ife and Ntekim et al 42 in Ibadan reported higher rates of $73.8 \%$ and $85 \%$ of secondary formal education in their patients [36, 37].

One should expect that good education should translate to early presentation and better awareness but the challenge most times is when there is lack of funds and patients not willing to have surgery.

The marital status of the participants showed that majority (85.7\%) were married and $2.8 \%$ were single. $11.5 \%$ of the population were widowed and divorced. A similar result was seen in a study by Jignasal Amrutal (2016) where $81 \%$ of the population was married and $3.5 \%$ were single [38]. A similar study by Usama $\mathrm{M}$ et al which revealed that majority $(60.8 \%)$ were married, $24.4 \%$ were divorced or widowed and $14.8 \%$ were single. In a Swiss population based study $61.4 \%$ were married, $12.6 \%$ were single and 26\% were widow/divorced [33].

In a study by Barry $\mathrm{A}$. et al it showed that $62.3 \%$ were single and $37.7 \%$ were married [39].

The stage of the disease at presentation was noted. In this study majority $44.5 \%$ presented with stage 3 while $43 \%$ presented with stage 4 and $1 \%$ came in stage 1 . In a study in India majority $54 \%$ came in late stage [40].

In another study $45.7 \%$ of the population came in stage 4 .

${ }^{36}$ this shows that most women present late and with advance form of the disease.

The commonest site of metastasis in breast cancer is usually the lungs. In this study the commonest site of metastasis is the lungs (69\%). The spread to the liver (5\%), Bone (8\%), Brain (2.5\%) and other sites (19\%).

The relationship between parity and breast cancer was seen in this study. Majority $39 \%$ of the study population had 3 children while $5.7 \%$ were Nulliparous. This is similar to a study in United States of America where those that had 1 to 4 children accounted for $24.5 \%$ and $6 \%$ were Nulliparous [35].

In a study in Baghdad $41.6 \%$ were nulliparous while $58.4 \%$ were multiparous [32].

In a study in Ekiti it was found that majority (76.8\%) were multiparous [41]. 
There are several literatures that have noted that Nulliparity is an associated risk factor to breast cancer but this study shows that many of the women were not nulliparous.

About one third of the women were menopausal at presentation. This finding was similar to the study reported by Olaogun et al [26] Anyanwu et al [42] in south-Eastern part of Nigeria.

The commonest site at presentation in our study was the right breast (50\%) followed by Left breast (44\%) and 5.5\% accounted for bilateral breast cancer. In a study in Jordan majority $(49.2 \%)$ of the women had left breast cancer and $46.5 \%$ for right breast cancer [31]. In a study done in Central African Republic revealed that many of the breast cancer cases occurred in the left breast [30].

In this study $99 \%$ of the populations were females while males accounted for $1 \%$. A study in Morocco revealed similar result. It showed that males accounted for $0.94 \%$ [37] In a similar study in Ekiti, it showed that male breast cancer accounted for $1.2 \%$ of the cases [38] This conforms to what has been documented by many studies in the literature.

Invasive ductal carcinoma still remains the commonest pathological form of breast cancer. In this study it accounted for $93.3 \%$ of all the histological types seen. This is followed by Invasive lobular carcinoma $(2.5 \%)$. Others are medullary $(0.5 \%)$, Papillary $(0.5 \%)$ and spindle cell carcinoma $(0.7 \%)$. In a study by Barry A. Miller et al majority (73.4\%) was Invasive ductal carcinoma, invasive lobular carcinoma (13.2\%) while Mucinous carcinoma accounted for 2.5\% [35].

In another study Invasive ductal carcinoma accounted for $64.9 \%$ [43].

In this study majority of the population were Christians $(90.5 \%)$, Muslim $(8.7 \%)$ and others $(0.75 \%)$. This was similar to the study by Olaogun et al. Though religion does not have much to do with the aetiopathogenesis of breast cancer, it affects the impact of presentation to the hospital. Many of these patient live in self-denial and seek spiritual help this may cause delay in presentation.

\section{Conclusion}

The prevalence of Breast cancer in our setting is high and most of the women with breast cancer are premenopausal presenting at the advance stage of the disease. The late presentation is not basically associated with the level of education. There are socio-demographic factors associated with breast cancer and these factors are not dependent orassociated with the increase in prevalence. There is need for more awareness to encourage early presentation.

(What this study adds); this study highlighted the peak age of breast cancer at the $4^{\text {th }}$ decade in our environment, with a bimodal age distribution at the $3^{\text {rd }}$ and $5^{\text {th }}$ decade.

Majority of the participants had a high level of education but this does not translate to better knowledge and awareness of the disease. Thus paradox of highly educated individual presenting at a late stage of the disease may persist.

Known facts about this topic; Late stage presentation of
Breast cancer is still the main challenge in Nigeria. Sociodemographic factors have major roles to play in the prevalence and presentation of Breast cancer.

\section{Competing Interest}

The authors declare no competing interest.

\section{References}

[1] Mensah S, Dogbe J, Kyei I, Addofoh N, Paintsil V, Osei Tutu L (2013) Determinants of late presentation and histologic types of Breast cancer in women presenting at teaching hospital in Kumasi, Ghana. Journal of cancer prevention and current research. elSSN 2373633X Vol 3 Issue 4.

[2] Clegg-Lamptey J N, Baako BN, Badoe E A (2012) Principles and practice of surgery including Pathology in the tropics. $4^{\text {th }}$ edition. Pp 488-519.

[3] Mohite RV, Mohite VR (2015) Sociodemographic and clinical profile of women with Breast cancer: A cross sectional study from western Maharashtra, India. International Journal of Health sciences ISSN: 2249-9571.

[4] Ibrahim N A, Oludara M A, Socio demographic factors and reasons associated with delay in breast cancer presentation. A study in Nigerian women 21 (3): 416-418.

[5] Sunday O. Olarenwaju MPA, Emmanuel O, Oyekunle PhD Adebukola O. Bamiro mph, Effects of socio-demographic variables on patients and diagnosis delay of Breast cancer at foremost Health care Instituition in Nigeria. Global Oncol. 2019 ny American Society of Clinical Oncology. Accepted july $2019 . \quad$ Ascopub.org/journal/jgo http/://doi.org/10.1200/jgo.19.10.108.

[6] Odunsanya O. O, Olufemi O. T, A study of knowledge, attitude and practice of nurses on breast cancer in Lagos. Nigeria, aiata. Oncol J. 41: 844-848, 2001.

[7] Nigerian federal ministry of health. Nig National Cancer Control plan. 2018-2022. http/plans/NCCP- final\% 20\% 55BI\% 5Dpdf.

[8] Armdt V, Feller A, Hauri D et al. Swiss cancer report (2015)Current situation and developments federal statistical office (FSO) 2016.

[9] Jedy-Agba E. McCornack V. Adebamowo C et alStage of diagnosis of breast cancer in sub Saharan Africa. A systemic review and meta-analysis Lancet. Glob. Health 4: e923-935. 2016.

[10] Pace L. E, Mpuga T, Hatengekimana V. et alDelay in breast cancer presentation and diagnosis at two rural cancer referral centers in Rwanda. Oncologist 20: 781-788 2015.

[11] Anita Feller, Kurt Schmidlin, Andrea Burdon, Christine Bouchardy, Jean-Luc Bulliard, Bertrand Camey, Isabelle Konzelmann, ManuellaMaspoli, Miriam Wanner, Kerri M. Clough-Gorr for NSC and NICER working group. Socioeconomic and demographic disparities in Breast cancer stage at presentation and survival: A swiss population based study. UICC global cancer control. International Journal of cancer (2017) Socioeconomic and demographic disparities in Breast cancer stage at presentation and survival: A swiss population based study. 
[12] Ajekigbe A TFear of mastectomy the most common factor responsible for late presentation of breast cancer in Nigeria. Clin Oncol (R CollRadiol) 3 (2) 78-80.

[13] Clegg- Lamptey J, Hodasi WA study of breast cancer in Korle $\mathrm{Bu}$ Teaching Hospital. Assessing the impact of health education Ghana med J 41 (2) 72-77.

[14] OheneYeboah M, Adjei EBreast cancer in Kumasi Ghana Ghana med Journal 46 (1) 8-13.

[15] Odusanya OO, Tayo OO (2013).

[16] Somdata P, Baridalyne N, Awareness of breast cancer in women of an urban resettlement colony. Indian journal of cancer 45 (4) 149-153.

[17] Alhurisi S, Lim J N W, Potrata B, West R, Factors influencing late presentation for breast cancer in the middle east. A systemic review Asian Pac J Cancer Prev. 12 (3) 1597-1600.

[18] Marcus TS, Lunda S, Fernandez L. Delayed breast cancer presentation hospital data with proactive care Afri J Prim. Health care Fam. Med 5 (1).

[19] Lannim DR, Mathew HF, Mitchel J, Swanson MS, Swanson FH.

[20] Influence of socioeconomic and cultural factors on Racial Dfferences in late stage presentation of breast cancer. JAMA 279 (22): 1801-1807.

[21] Breast cancer knowledge, attitudes, and practice among nurses in Lagos, Nigeria. Acta Oncol 40 (7) 844-888.

[22] Murray CJ, Frenk J. A framework of assessing the performance of health system Bulls world health organ 2000: 78: 7: 717-31.

[23] Woods LM, Rachet B, Coleman MP. Origins of socioeconomic inequalities in cancer survival: A review Ann. Oncol 2008: 17: 5-19.

[24] M. T. Agyei-Frempong, F. N. Ghartey, S. Asantepoku, B. Wiafe-Addai. A cross sectional view of estrogen receptor in 32 human breast cancer tissue in Ghana. Journal of Medical Science. Vol 8. No4. P420-424. 2008.

[25] Jha P, Ranson MK, Nguyen SN, Yach D. Estimates of global and regional smoking prevalence by age and sex. Am J Public Health 2002. 10002-10006.

[26] Jignasa Amrutal Sathwara, Ganesh Balasubramariam, SushanaSaoba Socio- demographic factors and late stage diagnosis of Breast cancer in India. (2016).

[27] ElimaJedy-Agba, Maria Paula Curado, Olufemi Ogunbiyi, Emanuel Oga, Toyin Fabowale et al. Cancer Incidence in Nigeria; A report from population based Cancer Registries. NIH Public access. Aurthor manuscript. Cancer Epidemiol. 2012 October (3615) e271-278 doi 10.1016/J can ep 2012.

[28] Jemal A, Bray F, Center M. M et al, Effects of age on the detection and management of Breast cancer (Bisel) 7. 908-929, 2015.

[29] Das U, Lakshamaiah K. C, Lokanatha D et al. Breast cancer in women younger than 35 years. A single center study. J. Mol. Biomark Diagn. 6.261, 2015.

[30] AugustinBaleakuzo, Pin Young, Epidemiology of Breast cancer, retrospective study in Central African Republic. BMC Public Health (2016) 16: 1230 doi 10: 1186/S12589-016-3863-6.

[31] Mohammed Tarawneh, Kamal Arquob, Ghazi Sharkas. Epidemiology and Survival Analysis of Lordanian Female breast cancer patients diagnosed from 1997-2002. Middle East journal of cancer 2011 22: 71-80.

[32] Usama M Al- fhadi, Ameel F Alshani, Ahmed S. Al- Nuaimi. Assesement of Sociodemographic characteristic in a sample breast cancer patients in Baghdad. JFac Mead Baghdad 2016 vol. 58. no 4.

[33] Annital Feller, Kurt Schmidlim, Andrea Bordini, Christine Bouchardy, Jean Luc- Bullard, Bertnand Caney, Isabelle Konzehnan, ManelaMaspoli, Minam Warner, Keri M CloujaGorr. International journal of cancer 147, 1529- 1539 (2017) uicc.

[34] Aleyana Mathew, Preethi Sara George, Kunnambath Ramadas, Beela Sarah Mathew, Aswim Kumar, LalithamaJayakumar Christopher M Booth. Sociodemographic and stage of cancer. (2015).

[35] Barry A Miller, Benjamin F Hankey, Terry L. Thomas. Impact of Sociodemographic, Hormone Receptor and Tumour grade on Ethnic difference in tumour stage and size for Breast cancer in US women. (2016).

[36] ShreshtaMalvia, SarangadharaAppalaraguBajadi, Uma S Dubey, SunitaSaxena. Epidemiology of Breast cancer in Indian women. Asia Pacific journal of clinical oncology 2017. Doi: $10.11 /$ ajco/2661.

[37] MeriemSlaju, RachidRanne, Azeddne Ibrahim, Mohammed Attaleb, Mohammed EL Mzibri, Mariam Amrani, Breast cancer in Morrocco. A literature Review (2017).

[38] Julius Gbenga Olaogun, John Adetunji Omotayo, Joshua TayeIge, Abidemi Emmanuel Omonisi, Olusoga OlusolaAkute, Olufunso Smisola Aduayi. Socio-demographic pattern of presentation and management outcome of breast cancer in a semi-urban tertiary institution. Pan African Medical Journal Research volume 36, Article 363. 28 Aug 2020/10.11604/pamj 2020, 36. 363. 17866.

[39] Bowen RL, Duffy SW, Ryan DA, Hart IR, Jones JL, Early onset of breast cancer in a group of british black women. Br. J Cancer 2008 Jan. 29. 98 (2): 277-81.

[40] Anyanwu SN.

[41] Breast cancer in eastern Nigeria. A ten year review. West African Journal Med. Apr-Jun 200019 (2) 120-5.

[42] Ntekim A, Nufu FT, Campbell OB, Breast cancer in young women in Ibadan, Nigeria. Afr health sci. 2009 Dec 9 (4) 242-6.

[43] Ogundiran TO, Ayandipo OO, Ademola AF, Adebamowo CA, Mastectomy for management of breast cancer in Ibadan, Nigeria. BMC Surg. 2013 Dec. 19, 13, 59. 